survive longer while undergoing dialysis it may become a greater problem, raising the question of whether it is justified to screen patients undergoing dialysis with a view to prophylactic nephrectomy. Computed tomography will show both cystic change and tumour formation and is probably the method of choice, ${ }^{22} 23$ though the changes can also be shown well by ultrasonography. In our patient the primary was clinically silent and a screening programme of asymptomatic patients undergoing dialysis would have been required to make the diagnosis before metastatic spread. As tumours may be bilateral and bilateral nephrectomy will seriously exacerbate anaemia assessment of malignant potential before nephrectomy is necessary. Size may be helpful and as this tumour is the largest we have seen in acquired cystic disease it might be argued that malignant spread was likely and death preventable by nephrectomy; screening of the older patients undergoing dialysis may therefore be justified.

We thank Dr S Golding, consultant radiologist who obtained the computed tomographic images in case 5 .

\section{References}

${ }^{1}$ Dunnill MS, Millard PR, Oliver DO. Acquired cystic disease of the kidneys: a hazard of long-term intermittent maintenance haemodialysis. f Clin Pathol 1977;30:868-77.

${ }^{2}$ Krempien B, Ritz E. Acquired cystic transformation of the kidneys of haemodialysed patients. Virchows Arch [Pathol Anat] 1980;386:189-200.

${ }^{3}$ Bansal VK, Ing TS, Ghejfee G, et al. Dialysis associated renal cystic degeneration (abstract). Kidney Int 1978;14:669.

${ }^{4}$ Mirahmadi MK, Vaziri ND. Cystic transformation of end-stage kidneys in patients undergoing hemodialysis. Int $\mathcal{f}$ Artif Organs 1980;3:267-70.

${ }^{5}$ Feiner HD, Katz LA, Gallo GR. Acquired cystic disease of kidney in chronic dialysis patients. Urology 1981;17:260-4.

${ }^{6}$ Fayemi AO, Ali M. Acquired renal cysts and tumours superimposed on chronic primary kidney diseases. Path Res Pract 1980;168:73-83.

${ }^{7}$ Hughson MD, Hennigar GR, McManus JFA. Atypical cysts acquired renal cystic disease, and renal cell tumours in end-stage dialysis kidneys. Lab Invest 1980;42:475-80.

${ }^{8}$ Hepler AB. Solitary cysts of the kidney. A report of 7 cases and observations on the pathogenesis of these cysts. Surg Gynecol Obstet 1930; 50:668-87.

${ }^{9}$ McManus JFA, Hughson MD, Fitts CT, Williams AV. Studies on end-stage kidneys. I. Nodule formation in intrarenal arteries and arterioles. Lab Invest 1977;37:339-49.

${ }^{10}$ Carone FA, Rowland RG, Perlman SG, Ganote CE. The pathogenesis of drug-induced renal cystic disease. Kidney Int 1974;5:411-21.

11 Gardner KD, Solomon S, Fitzgerrel WW, Evan AP. Function and structure in the diphenylamine-exposed kidney. $\mathcal{f}$ Clin Invest 1976; 57:796-806.

12 Evan AP, Gardner KD. Nephron obstruction in nordihydroguaiaretic acid-induced renal cystic disease. Kidney Int 1979;15:7-19.

${ }^{13}$ Anonymous. Acquired cystic disease of the kidney [Editorial]. Lancet 1977 ;ii:1063.

${ }^{14}$ Milutinovich J, Follette WC, Scribner BH. Spontaneous retroperitoneal bleeding in patients on chronic hemodialysis. Ann Intern Med 1977; $\mathbf{8 6}: 189-92$.

${ }^{15}$ Bhasin HK, Dana CL. Spontaneous retroperitoneal hemorrhage in chronically hemodialyzed patients. Nephron 1978;22:322-7.

${ }^{16}$ Kassirer JP, Gang DL. Hypotension and flank pain in a man with chronic renal failure. $N$ Engl 7 Med 1982;306:975-84.

${ }^{17}$ Rizk GK, Atallah NK, Bridi GI. Renal arteriovenous fistula treated by catheter embolization. Br $\mathcal{F}$ Radiol 1973;46:222-4.

18 Goldsmith HJ, Ahman R, Raichura N, et al. Association between rising haemoglobin concentration and renal cyst formation in patients on long-term regular haemodialysis treatment. Proc Eur Dial Transplant Assoc 1982;19:313-8.

19 Charles G, Lundin III AP, Delano BG, Brown C, Friedman EA. Absence of anemia in maintenance hemodialysis. Int $\mathcal{F}$ Artif Organs 1981;4: 277-9.

${ }^{20}$ Bell ET. Renal diseases. Philadelphia: Lea and Febiger, 1950:428.

${ }^{21}$ Evins SC, Varner W. Renal adenoma-a misnomer. Urology 1979;13: 85-6.

${ }^{22}$ Ischikawa I, Saito Y, Onouchi Z, et al. Development of acquired cystic disease and adenocarcinoma of the kidney in glomerulonephritic chronic haemodialysis patients. Clin Nephrol 1980;14:1-6.

${ }^{23}$ Bommer J, Waldhen R, van Kaick G, Strauss L, Ritz E. Acquired renal cysts in uremic patients-in vivo demonstration by computed tomography. Clin Nephrol 1980;14:299-303.

(Accepted 14 September 1983)

\title{
Influence of imaginative teaching of diet on compliance and metabolic control in insulin dependent diabetes
}

\author{
D K McCULLOCH， R D MITCHELL，J AMBLER， R B TATTERSALL
}

\begin{abstract}
Dietary non-compliance is an important cause of poor metabolic control in insulin dependent diabetes. Patients are often blamed, but teaching methods may be at fault, so a prospective study was set up to compare the effect of three different teaching methods. After a three month run in, 40 adults with longstanding poorly controlled insulin dependent diabetes (mean haemoglobin $A_{1} 13.0 \%$ ) were allocated at random to three teaching methods: conventional diet sheet instruction (group 1); practical lunchtime demonstrations (group 2); videotape education (group 3). Knowledge was assessed by questionnaires, compliance by seven day food records, and glycaemic control by serial glycosylated haemoglobin measure-
\end{abstract}

Department of Diabetes, University Hospital, Nottingham

D K MCCULLOCH, MRCP, research fellow

R D MITCHELL, BSC, dietitian

J AMBLER, MSC, PHD, principal biochemist

R B TATTERSALL, MD, FRCP, consultant physician

Correspondence to: Dr R B Tattersall. ments. During six months of follow up there was no improvement in knowledge, compliance, or $\mathrm{HbA}_{1}$ in group 1, but in groups 2 and 3 both knowledge and compliance improved. In group $2 \mathrm{HbA}_{1}$ fell to $10 \cdot 6$ (SD $2 \cdot 1) \%$ and in group 3 to $9 \cdot 6(2 \cdot 3) \%$. The change in $\mathbf{H b A}_{1}$ showed an appreciable correlation with dietary compliance as judged by day to day consistency in carbohydrate intake.

These findings show that new and interesting educational methods can have a major influence on knowledge, compliance, and metabolic control in insulin dependent diabetes.

\section{Introduction}

For patients treated with insulin to achieve and maintain good diabetic control they need to pay attention simultaneously and continuously to many variables including insulin dose, correct site of injection, and the effects of exercise and diet. ${ }^{1}$ Rollo in $\mathbf{1 7 9 8}$ was the first to point out that patients find it very difficult to adhere to prescribed dietary restrictions. ${ }^{2}$ Yet, however many advances have been made in the treatment of 
diabetcs over the past two centuries, the problem of dietary non-compliance has been rediscovered every time it has been looked for. ${ }^{3-13}$ The extent to which the actual eating habits of patients deviate from their theoretical dietary prescription is surprisingly large and has prompted some authors to suggest that dietary policies should be simplified and made more flexible to suit the patient's lifestyle. ${ }^{313-15}$

The aims of this study were to compare the effects of three teaching methods on the knowledge, compliance, and glycaemic control among adults with longstanding poorly controlled insulin dependent diabetes.

\section{Patients and methods}

To be included in the study patients had to be between 16 and 65 years and to have been taking insulin for at least four years. Their current insulin regimen had to be at least two injections daily of short and intermediate acting insulin and they had to have had at least two estimations of haemoglobin $A_{1}\left(H_{b} A_{1}\right)$ in the previous 12 months greater than $12.0 \%$ (the upper limit of the normal range in our laboratory being $8.5 \%$ ).

We wrote to 143 patients who fulfilled the above criteria explaining the purpose of the study and what their participation would entail. Eighty three replied, of whom 52 wished to take part. Eight patients dropped out during the run in period and a further four during the intervention period. The latter comprised one patient from group 1, one from group 2 , and two from group 3 (see below). They did not differ from those who completed the study in terms of age, duration of diabetes, or $\mathrm{HbA}_{1}$. Three dropped out because of intercurrent illness (exacerbation of epilepsy, vitreous haemorrhage, and a road traffic accident) and one because of pressure of work. Thus 40 patients (23 men, 17 women) completed all aspects of the study. Their mean age was 35 (range 17 to 64 ) years and mean duration of diabetes 12 (range 4 to 26) years. Twenty nine were of normal weight (body mass index between $19.1 \mathrm{~kg} / \mathrm{m}^{2}$ and $24.9 \mathrm{~kg} / \mathrm{m}^{2}$ ), one was underweight (body mass index less than $19 \cdot 1 \mathrm{~kg} / \mathrm{m}^{2}$ ), and 10 were overweight (body mass index greater than $24.9 \mathrm{~kg} / \mathrm{m}^{2}$ ).

The study began with a run in period of three months during which an attempt was made to improve overall diabetic treatment as much as possible without mentioning diet. Patients were told about the value of long term normal glycaemia and how this could be assessed by regular blood glucose recordings at home and $\mathrm{HbA}_{1}$ estimations. They were taught to measure blood glucose before each meal and before bedtime on two days a week using BM 20-800 strips, and to adjust their own insulin regimens on the basis of the results. They were given the target of achieving and maintaining glucose values at these times of 4-8 mmol/1 $(72-144 \mathrm{mg} / 100 \mathrm{ml})$ if this was possible without provoking unacceptably frequent hypoglycaemia. Each patient was also told what his $\mathrm{HbA}_{1}$ concentration was at each visit and that our aim should be to keep this below $10 \%$.

Patients were then allocated into one of three groups for dietary education. Group 1 (14 patients) were given conventional dietary teaching, group 2 (13 patients) were given a lunchtime demonstration, and group 3 (13 patients) were given a videotape demonstration. Dietary policy was the same for all patients and was kept as simple as possible to encourage compliance. An appropriate total daily intake of carbohydrate was determined jointly by the patient and dietitian taking into account previous eating habits, age, weight, and lifestyle. This was then broken down into $10 \mathrm{~g}$ carbohydrate exchanges. Patients were asked to keep to an agreed distribution of carbohydrate exchanges in the form of three main meals and three snacks. Variety in the actual carbohydrate containing foods to be eaten each day was achieved by giving each patient lists of common food stuffs (expressed in grams/ounces and household measures) containing $10 \mathrm{~g}$ carbohydrate. No emphasis was placed on reducing fat or increasing fibre intake. Restriction of energy was advised, however, in the overweight. The overriding concept we tried to impart to the patient was that they should eat the same amount of carbohydrate at the same times each day and adjust their insulin regimen around this "consistent carbohydrate profile" to achieve the blood glucose and $\mathrm{HbA}_{1}$ targets described above. Three different methods of dietary education were used.

Group 1-These patients were assessed by a dietitian and received individual tuition about what carbohydrate distribution would be appropriate for them. In addition to a pamphlet containing $10 \mathrm{~g}$ exchange lists they were given simple menus to emphasise the carbohydrate profile they should stick to from day to day.
Group 2-In addition to the individual assessment and dietary pamphlet described for group 2, these patients were asked to come to the hospital canteen in groups of four or five (with accompanying spouse and children if possible) where they had lunch with both dietitian and doctor. These sessions were in two parts. Firstly, patients were asked to help themselves to a variety of hot and cold dishes and to make up their carbohydrate allowance to what had been prescribed for them previously. Any mistakes were corrected by the dietitian and problems of guessing or measuring were discussed. After lunch they were shown a display of other items of food (including breakfast food, snacks, etc) so that they could see and feel exactly how much of each item did in fact contain $10 \mathrm{~g}$ carbohydrate. Scales were provided to verify the weight of slices of bread etc. Specimen meals were also laid out and each patient asked to guess the carbohydrate content. Over the course of their three lunchtime visits they were exposed to a wide variety of foods which they might encounter at various times of the day in their own lives.

Group 3-In addition to the individual assessment and dietary pamphlet as described for group 1 these patients were shown a 24 minute videotape- "Healthy eating and diabetes" prepared by the audio visual department, University Hospital. This was viewed on three separate occasions while sitting in an arm chair in a quiet room, and without dietitian or doctor being present. The videotape began with an explanation of the importance of eating a balanced diet and maintaining a consistent carbohydrate profile. It then took the viewer through a day in the life of two insulin treated patients with very different dietary requirements and lifestyles. The tape showed what food each patient ate at each meal and snack, building up a different "carbohydrate profile" for each. It ended by suggesting that the viewer should try to work out his or her own carbohydrate profile with the dietitian's help. Patients in all three groups were seen for dietary instruction three times during the six month intervention period.

Dietary knowledge was tested by two questionnaires, one at the end of the run in and the other at the end of the intervention period. The questions were similar, but not identical, on both occasions and tested the patient's understanding of his or her own diet. They were asked to say how many $10 \mathrm{~g}$ exchanges of carbohydrate they ate each day and what steps they took to make sure these were measured accurately. Finally, they were asked specific questions about the number of $10 \mathrm{~g}$ carbohydrate exchanges contained in several common foods, including items in their carbohydrate exchange list. The maximum possible score on each questionnaire was 20 points.

Dietary compliance was assessed from detailed seven day food records at the end of the run in and intervention periods. Since the aim of the education was to encourage day to day consistency in the amount of carbohydrate eaten at each meal and snack, the data derived from the seven day food records were handled as follows for each patient. The amount of carbohydrate taken at each of the seven breakfasts was calculated. The coefficient of variation was then derived by (standard deviation $/$ mean) $\times 100$. This calculation was repeated for all seven morning snacks, lunches, mid-afternoon snacks, evening meals, and bedtime snacks. In this way, six coefficients of variation were derived for each patient. An average of these was then calculated to give one single figure, the overall coefficient of variation for each food record, which therefore gives a measure of the day to day consistency in eating habits for that patient.

Metabolic control was assessed by the serial $\mathrm{HbA}_{1}$ measurements using an electrophoretic method on cellulose acetate membrane. ${ }^{16}$ The coefficient of variation for this method is less than $6 \%$ where $\mathrm{HbA}_{1}$ is less than $10 \%$ of total $\mathrm{HbA}$ and is less than $4 \%$ where $\mathrm{HbA}_{1}$ is greater than $14 \%$ of total $\mathrm{HbA}$. Patient samples were measured in duplicate, and $\mathrm{HbA}_{1}$ control (Glycophore control product No 51262, Gelman Sciences Ltd) run on each membrane. Where duplicate samples differed by more than $1 \%$, the analysis was repeated.

Paired non-parametric statistical tests were used. Changes in questionnaire score, overall coefficient of variation for carbohydrate consistency, and $\mathrm{HbA}_{1}$ between groups 1,2 , and 3 were tested using the Mann-Whitney method while the relation between change in $\mathrm{HbA}_{1}$ and change in overall coefficient of variation for carbohydrate consistency (figure 1) were determined with the KendallRank method.

\section{Results}

Table I shows the characteristics of patients in groups 1,2 , and 3 . There were no significant differences between the groups with 
respect to age/sex distribution, duration of diabetes, insulin dose, $\mathrm{HbA}_{1}$, or body mass index at the start of the study.

Table II shows the changes within each group during the six month intervention period. There were no significant changes in insulin dose or body mass index. Dietary knowledge was equally poor in all three groups at the time of the first questionnaire. When asked how

TABLE I-Characteristics of patients allocated to three methods of dietary education. Figures are mean $(S D)$

\begin{tabular}{|c|c|c|c|}
\hline & $\begin{array}{l}\text { Group } 1 \\
(n=14)\end{array}$ & $\begin{array}{c}\text { Group } 2 \\
(n=13)\end{array}$ & $\begin{array}{c}\text { Group } 3 \\
(n=13)\end{array}$ \\
\hline $\begin{array}{l}\text { Men } \\
\text { Women } \\
\text { Age (years) } \\
\text { Duration of diabetes (years) } \\
\text { Insulin dose (U/kg per day) } \\
\text { Initial HbA }(\%) \\
\text { Body mass index }\left(\mathrm{kg} / \mathrm{m}^{2}\right)\end{array}$ & \begin{tabular}{cc}
\multicolumn{2}{c}{8} \\
\multicolumn{2}{c}{6} \\
$35 \cdot 6$ & $(10 \cdot 4)$ \\
$10 \cdot 9$ & $(6 \cdot 1)$ \\
$0 \cdot 68$ & $(0 \cdot 25)$ \\
$12 \cdot 9$ & $(1 \cdot 6)$ \\
$24 \cdot 0$ & $(3 \cdot 0)$
\end{tabular} & \begin{tabular}{cl} 
& \multicolumn{2}{c}{8} \\
& \\
$31 \cdot 6$ & $(8 \cdot 3)$ \\
$11 \cdot 8$ & $(5 \cdot 1)$ \\
$0 \cdot 79$ & $(0 \cdot 30)$ \\
$13 \cdot 0$ & $(2 \cdot 9)$ \\
$23 \cdot 3$ & $(2 \cdot 0)$
\end{tabular} & \begin{tabular}{cc}
\multicolumn{2}{c}{7} \\
\multicolumn{2}{c}{6} \\
$36 \cdot 5$ & $(15 \cdot 3)$ \\
$13 \cdot 4$ & $(6 \cdot 0)$ \\
0.78 & $(0 \cdot 17)$ \\
$12 \cdot 9$ & $(1 \cdot 3)$ \\
$23 \cdot 8$ & $(2 \cdot 9)$
\end{tabular} \\
\hline
\end{tabular}

None of the differences between groups 1,2 , and 3 are statistically significant.

TABLE II-Effect of three methods of dietary education on insulin dose, body mass index, knowledge, and compliance at the end of the run in period (initial) and at end of six month intervention period ( $f(n a l)$. Figures are mean $(S D)$

\begin{tabular}{|c|c|c|c|c|c|c|}
\hline \multirow[b]{2}{*}{$\begin{array}{l}\text { Insulin dose (U/kg per day): } \\
\text { Initial } \\
\text { Final* } \\
\text { Body mass index }\left(\mathrm{kg} / \mathrm{m}^{2}\right) \text {. }\end{array}$} & \multicolumn{2}{|c|}{$\underset{(n=14)}{\text { Group 1 }}$} & \multicolumn{2}{|c|}{$\underset{(n=13)}{\text { Group } 2}$} & \multicolumn{2}{|c|}{$\underset{(n=13)}{\text { Group } 3}$} \\
\hline & $\begin{array}{l}0.68 \\
0.68\end{array}$ & $\begin{array}{l}(0.25) \\
(0.24)\end{array}$ & $\begin{array}{l}0.79 \\
0.76\end{array}$ & $\begin{array}{l}(0.30) \\
(0.23)\end{array}$ & $\begin{array}{l}0 \cdot 78 \\
0 \cdot 78\end{array}$ & $\begin{array}{l}(0 \cdot 17) \\
(0 \cdot 18)\end{array}$ \\
\hline $\begin{array}{l}\text { Body mass index }\left(\mathrm{kg} / \mathrm{m}^{2}\right) \text { : } \\
\text { Initial } \\
\text { Final* }\end{array}$ & $\begin{array}{l}24 \cdot 0 \\
23.9\end{array}$ & $\begin{array}{l}(3 \cdot 0) \\
(2 \cdot 3)\end{array}$ & $\begin{array}{l}23 \cdot 3 \\
23 \cdot 7\end{array}$ & $\begin{array}{l}(2 \cdot 0) \\
(1 \cdot 7)\end{array}$ & $\begin{array}{l}23 \cdot 8 \\
23 \cdot 8\end{array}$ & $\begin{array}{l}(2 \cdot 9) \\
(2 \cdot 0)\end{array}$ \\
\hline $\begin{array}{l}\text { Questionnaire score } \\
\text { (maximum possible }=20 \text { ): } \\
\text { First } \\
\text { Second* } \\
\text { Food record: }\end{array}$ & $\begin{array}{r}10 \cdot 5 \\
8.0\end{array}$ & $\begin{array}{l}(3 \cdot 6) \\
(4 \cdot 3)\end{array}$ & $\begin{array}{l}11 \cdot 1 \\
15 \cdot 9\end{array}$ & $\begin{array}{l}(3 \cdot 2) \\
(2 \cdot 8) \S\end{array}$ & $\begin{array}{l}10 \cdot 6 \\
17 \cdot 4\end{array}$ & $\begin{array}{l}(3 \cdot 5) \\
(2 \cdot 1) \S\end{array}$ \\
\hline $\begin{array}{l}\text { First }{ }^{*} \\
\text { Second* } \\
\text { OCV }(\%)\end{array}$ & $\begin{array}{l}52 \cdot 8 \\
53 \cdot 5\end{array}$ & $\begin{array}{l}(19 \cdot 6) \\
(27 \cdot 6)\end{array}$ & $\begin{array}{l}64 \cdot 1 \\
47 \cdot 4\end{array}$ & $\begin{array}{l}(23 \cdot 2) \\
(20 \cdot 5)\end{array}$ & $\begin{array}{l}52 \cdot 4 \\
23 \cdot 6\end{array}$ & $\begin{array}{l}(31 \cdot 1) \\
(14 \cdot 7) \ddagger\end{array}$ \\
\hline
\end{tabular}

*At nine months.

+See text for explanation.

$\left.\begin{array}{l}\ddagger \mathrm{p}<0.01 \\ \mathrm{p}<<0.001\end{array}\right\}$ compared with group 1 (Mann-Whitney U test).

$\mathrm{OCV}=$ Overall coefficient of variation.

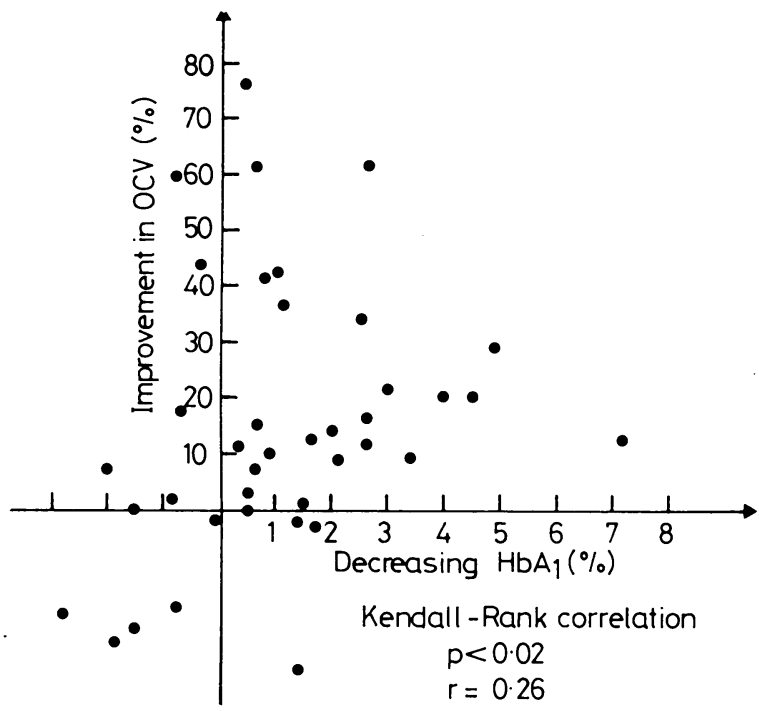

FIG 1 -Correlation between change in $\mathrm{HbA}_{1}$ and change in day to day dietary consistency among 40 insulin dependent adults. $\mathrm{OCV}=$ overall coefficient of variation.

many carbohydrate exchanges they ate each day, only $21(52 \%)$ of the patients gave an answer, and less than one third of these answers was correct when compared with their seven day food records. There was widespread ignorance about the difference between energy and carbohydrate. Over one third thought that fried bacon counted as a carbohydrate exchange whereas grilled fish did not.
In the second questionnaire, however, there was no improvement in knowledge in group 1, but patients in both other groups scored very much higher $(\mathrm{p}<0.001)$. Day to day dietary consistency was equally poor in all three groups during the run in. The mean overall coefficient of variation for carbohydrate profiles in the first seven day food records was over $50 \%$ in all three groups. Again, there was no significant improvement in group 1, but patients in both the other two groups showed significant reductions in day to day carbohydrate variation in the second food record $(p<0.01)$

Changes in mean $\mathrm{HbA}_{1}$ throughout the study are shown in fig 2 .

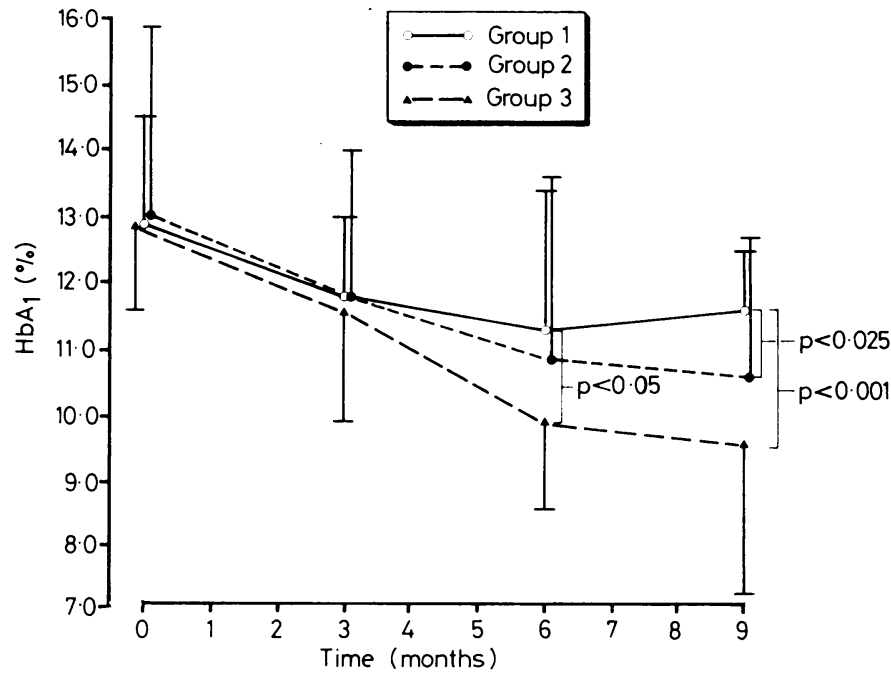

FIG 2-Change in $\mathbf{H b A}_{1}$ over nine months in patients receiving conventional dietary instruction (group 1), lunchtime demonstrations (group 2), or videotape education (group 3 ).

By the end of the run in, $\mathrm{HbA}_{1}$ in groups 1,2 , and 3 had fallen by a similar amount to $11.8(1.2 \%), 11.8(2.2 \%)$, and $11.6(1.7 \%)$ respectively. Three months later there was no further improvement in group 1 where $\mathrm{HbA}_{1}$ was $11.3(2 \cdot 1 \%) . \mathrm{HbA}_{1}$ in group 2 , however, had fallen to $10 \cdot 9 \pm 2 \cdot 7 \%$ while the videotape group 2 showed even more improvement at $9 \cdot 9 \pm 1 \cdot 3 \%$, significantly better than group 1 $(p<0.05)$. By the end of the six month intervention period haemoglobin $A_{1}$ in group 1 remained much the same at $11.6(0.9) \%$. Both groups 2 and 3 were significantly better than group 1 at this stage being $10.6(2.1) \%(p<0.025)$ and $9.6(2.3) \%(p<0.001)$, respectively.

To assess whether the improvement in haemoglobin $A_{1}$ was directly related to improved dietary compliance, the change in overall coefficient of variation for carbohydrate consistency between first and second food records was correlated with the change in $\mathrm{HbA}_{1}$ between the end of the run in and the end of the intervention period in each patient (fig 1). Though the points are widely scattered, there is significant correlation between the two (Kendall-Rank $r=0 \cdot 26$, $\mathrm{p}<0.02)$. Thus by and large where individual patients showed a substantial reduction in $\mathrm{HbA}_{1}$ during the intervention period, this was associated with a substantial improvement in their day to day carbohydrate consistency, as measured by a reduction in the overall coefficient of variation.

\section{Discussion}

This study has shown that even patients with long standing poorly controlled insulin dependent diabetes can show a big improvement in dietary knowledge and compliance when imaginative educational techniques are used, and that these changes are reflected in improved metabolic control. Not all the improvement in control is the result of the intervention; the mean $\mathrm{HbA}_{1}$ in all three groups dropped by $1.1 \%$ during the run in period and this beneficial effect of "being in a study" is probably related to the increased attention patients receive rather than to the specific techniques that are taught. ${ }^{1718}$ Worth et al showed that $\mathrm{HbA}_{1}$ in a similar group of patients tended to fall steadily over the first six months of the study 
but then rose to "prestudy levels" by nine months. ${ }^{17}$ This pattern was certainly seen in our patients in group 1 and was disappointing. After all, repeated individual tuition supplemented by dietary pamphlets and sample menus is the method used in most diabetic clinics throughout the country. It may work in newly diagnosed patients but perhaps with a group of patients with longstanding poorly controlled diabetes, such as those in this study, it is too uninteresting to stimulate their interest in the long term.

The improvement in the other two groups cannot simply be ascribed to the increased attention of being in a study. Apart from improved glycaemic control, the patients in these groups showed better understanding in all aspects of dietary management. One can only speculate what particular aspects of the educational methods used for groups 2 and 3 were particularly beneficial; certainly patients commented that they enjoyed being taught in small groups, particularly when members of their own family could be present. Weinsier et al ${ }^{19}$ in a study of older patients with non-insulin dependent diabetes found that long term cooperation was improved by small group orientated teaching, frequent follow up, feedback to patients of laboratory data, individualisation of diet prescriptions, and family involvement. Our study endorses these findings. Several patients also said they found it much easier to understand the concept of carbohydrate exchanges when shown real food containing $10 \mathrm{~g}$ carbohydrate, rather than simply being given a printed diet sheet.

The extent of the improvement shown in this study is surprising as the dietary advice given was very simple. No attempt was made to change the type of food which patients enjoyed eating. Each patient played a major part in determining a carbohydrate distribution that suited him or her, a policy suggested by West ${ }^{12}$ and Nuttall..$^{15}$ The only point emphasised was that, once established, this pattern of eating should be repeated consistently from day to day. The importance of this simple aspect of diet therapy in insulin dependent diabetes has been suggested by others ${ }^{1416}$ but it is often forgotten by the proponents of more complex dietary strategies. Unfortunately, though lip service has been paid to these practical considerations in the new recommendations by both the American and British Diabetic Associations, in reality dietary prescriptions have Dietary policies on the North American continent are even more complex, entailing up to six different exchange lists requiring understanding of protein, fat, and calories as well as carbohydrate. In addition, the new recommendations proposed by the diabetic associations in the United States, Canada, and Britain will mean major changes in the structure of the diets that patients are prescribed. The results of this study indicate that substantial improvement in understanding and compliance can be achieved by much simpler diet recommendations and that the main reason why diet usually fails ${ }^{12}$ is not that the diet is wrong but that methods of teaching it and maintaining interest are ineffective.

The videotapes as used in our study should not replace the work of dietitians since the two complement one another. A become more confusing and more complicated in recent years. videotape has the advantage that it can convey basic information in a form that is appealing and easy to understand. It can also be repeated as often as necessary which will allow dietitians to spend more time on individual counselling and practical food demonstrations. These methods could easily be applied in most diabetic clinics and should be more effective than the traditional printed diet sheet and lecture from the dietitians.

This study was supported by a British Diabetic Association development project grant. DKMcC is a research fellow funded by the British Diabetic Association. Copies of the videotape "Healthy eating and diabetes" ( 25 minutes) can be obtained in any format from Mrs M Cumpstey, Audiovisual Department, Queens Medical Centre, Nottingham, at a cost of $£ 50$.

\section{References}

1 Tattersall RB. Modern management of the insulin-dependent diabetic. Ir 7 Med Sci 1979;148 suppl 2:45-53.

${ }^{2}$ Rollo J. Cases of the diabetes mellitus: with the results of the trials of certain acids and other substances in the cure of the Lues Veneria. London: C Dilly, 1798

3 Tunbridge RE. Sociomedical aspects of diabetes mellitus. Lancet 1953;ii: 893-9.

4 Stone DB. A study of the incidence and causes of poor control in patients with diabetes mellitus. Am 7 Med Sci $1961 ; 241$ :436-41.

5 Bloom A. Relationship of the complications of diabetes to the clinical state. Proc $R$ Soc Med 1967;60:149-52.

${ }^{6}$ Williams TF, Anderson E, Watkins JD, Coyle V. Dietary errors made at home by patients with diabetes. $\mathcal{F}$ Am Diet Assoc 1967;51:19-25.

${ }^{7}$ Fuchsberg RR. The diabetes supplement of the national health survey. II Methods and techniques. $\mathcal{F}$ Am Diet Assoc 1968;52:121-4.

8 Holland WM. The diabetes supplement of the national health survey. III The patient reports on his diet. F Am Diet Assoc 1968;52:387-90.

9 Stulb SC. The diabetes supplement of the national health survey. IV The patient's knowledge of the food exchanges. F Am Diet Assoc 1968;52: 391-3.

10 Tunbridge RE, Wetherill JH. Reliability and cost of diabetic diets. Br Med f 1970;ii:78-80.

$11 \mathrm{Hsu} \mathrm{N}$, Gormican A. The computer in retrieving dietary history data. f Am Diet Assoc 1973;63:402-7.

12 West KM. Diet therapy of diabetes: an analysis of failure. Ann Int Med 1973;79:425-34.

13 McCulloch DK, Young RJ, Steel JM, Wilson EM, Prescott RJ, Duncan LJP. Dietary compliance and metabolic control in insulin-dependent

${ }^{14}$ Strauss MB. Diabetic regimens-procrustean beds? $N$ Engl f Med $1969 ; 281: 1484-6$.

15 Nutall FQ. Diet and the diabetic patient. Diabetes Care 1983;6:197-207.

${ }^{16}$ Ambler J, Walker G, Janik B. Measurement of glycosylated haemoglobin on cellulose acetate membrane. Clin Chem 1983;29:340-3.

17 Worth R, Home PD, Johnston DG, et al. Intensive attention improves glycaemic control in insulin-dependent diabetes without further advantage from home blood glucose monitoring: results of a controlled trial. Br Med f 1982;285:1233-40.

18 Reeves ML, Seigler DE, Ryan EA, Skyler JS. Glycaemic control in insulin-dependent diabetes mellitus: comparison of outpatient intensified conventional therapy with continuous subcutaneous insulin infusion. Am f Med 1982;72:673-80.

19 Weinsier RL, Seeman A, Herrera MG, Simmons JJ, Collins ME. Diet therapy of diabetes. Description of a successful methodologic approach to gaining diet adherence. Diabetes $1974 ; 23: 669-73$.

(Accepted 16 September 1983) diabetics. Human Nutrition: Applied Nutrition 1983;37A :287-92.

W

A fit, active woman of 55 has had a persistently low blood pressure of $80 / 50$ for many years. This was discovered at a routine examination and she was refused life assurance because of this. The patient has never complained of any symptoms and is not anaemic. Should anything be done for her?

There is a regrettable tendency to associate low blood pressure with symptoms and, as this history illustrates, with a poor prognosis. The distribution of blood pressure in the population is such that a small percentage of people will have blood pressures well below the mean of the general population. With the exception of those few patients with an underlying disease leading to postural hypotension, or with Addison's disease, the evidence from the Framingham Study among others suggests that the lower the blood pressure the better

the prognosis. ${ }^{1}$ Shapiro has questioned the association of hypotension with symptoms -in short the acceptance of the entity as a disease-in the public's mind and among doctors, and he comments on the potential for iatrogenic illness. ${ }^{2}$ We can do no better than quote Robinson who as long ago as 1940 wrote: "There are no symptoms peculiar to or due to low blood pressure. ... Hypotension is not a disease; it is an ideal blood pressure level."3-VINCENT BRADY, medical registrar, and EOIN O'BRIEN, consultant physician (cardiology), Dublin. ${ }^{1}$ Kannel WB. Role of blood pressure in cardiovascular morbidity and mortality.
Prog Cardiovas Dis 1974;17:5-24.
${ }^{2}$ Shapiro MF. Low blood pressure: an extinct diagnosis. Can Med Assoc $\mathcal{F} 1982$;
$126: 887-8$.
${ }^{3}$ Robinson SC. Hypotension: the ideal normal blood pressure. N Engl $\mathcal{F}$ Med
$1940 ; 233: 407-16$. 